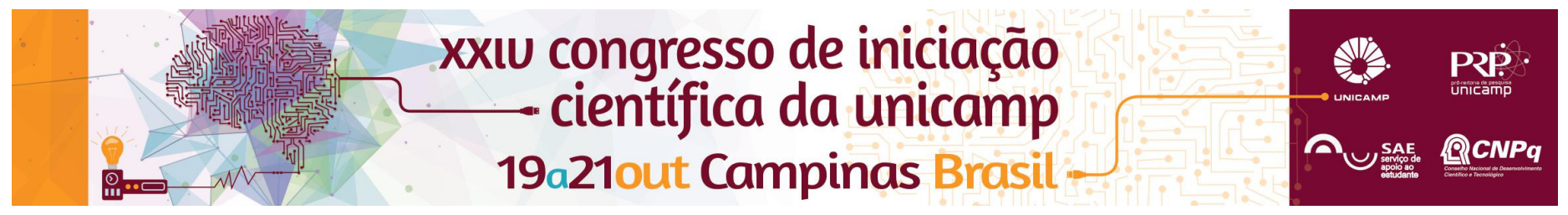

\title{
Promoção da saúde na vida de trabalhadores
}

\author{
Camila da Silva Bueno, Jessica dos Santos Lucia*, Letícia Mossanega Silva, Cintia Rachel Gomes Sales, \\ Valesca Nunes dos Reis, Rosana Evangelista Poderoso, Maria Inês Monteiro.
}

\begin{abstract}
Resumo
A produção de conhecimento sobre aspectos relacionados à saúde de trabalhadores é elemento basilar para promover conquistas e melhorias no âmbito dos ambientes e processos de trabalho. Com vistas a contribuir com a divulgação do conhecimento científico no campo da saúde e trabalho, foram produzidos e divulgados jornais eletrônicos sobre a temática, elaborado por alunas de ensino médio. Neste projeto foi possível gerar informação dos seguintes tópicos: conceito e estrutura do trabalho no Brasil, distúrbios osteomusculares, agrotóxicos na vida do trabalhador rural, sono e a má qualidade de vida, trabalho Infantil e diferença de gênero no mercado de trabalho. Como tópico extra as alunas elaboraram informações sobre o Zika vírus.
\end{abstract}

\section{Palavras-chave:}

Saúde do trabalhador, Comunicação e divulgação científica, Troca de informação em saúde.

\section{Introdução}

O desenvolvimento que a ciência proporciona para a humanidade pode ser divulgado de forma que a população em geral compreenda como sua própria condição de vida vai sendo transformada. No caso da saúde do trabalhador os esforços pretenderam fazer chegar aos trabalhadores reflexões sobre as condições que envolvem este universo. Deste modo, foram objetivos deste projeto: promover um espaço de discussão para estudantes de ensino médio sobre promoção a saúde no trabalho e disseminação/popularização da informação científica; reconhecer os problemas enfrentados pela comunidade de trabalhadores; e propor soluções baseadas nos problemas vivenciados. Aproveitamos também a situação de aumento de casos de Zika vírus para produzir conteúdo sobre este tópico como jornal extra.

\section{Resultados e Discussão}

Como forma de incluir estudantes de Ensino Médio nas ações de divulgação científica, nos baseamos em formas ativas de aprendizagem. Este método abrange as seguintes fases: o aluno entra em contato com a realidade a ser estudada; identifica os pontos chaves; teoriza; busca hipótese para solução do problema identificado e aplica na realidade vivenciada. Com isso, ocorre melhoria no aprendizado de modo que se sintam capazes de divulgar conhecimento sobre os aspectos relativos a saúde, trabalho e promoção à saúde de forma acessível à linguagem da população. As alunas tiveram participação ativa no processo de escolha dos assuntos e pesquisa sobre informação relevante ao tema. Com as informações em mãos as alunas elaboraram material educativo em forma de jornais disponíveis em site online.

No processo de seleção de informações as alunas foram capacitadas para realizar buscas de modo independente de informações confiáveis na internet em dois momentos: a princípio com supervisão aprenderam a pesquisar em sites governamentais, bases de dados Lilacs, Bireme, Scielo e Pubmed, após essa aprendizagem, no segundo momento, passaram a pesquisar de forma autônoma nas ferramentas que aprenderam anteriormente.
Abaixo imagens do site e jornais publicados:

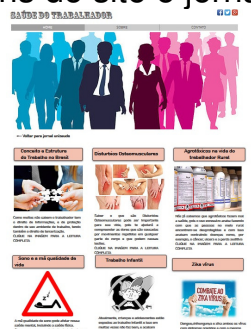

Figura 1. Site: http://jornalunisaude.wix.com/saude-do-trabalhador

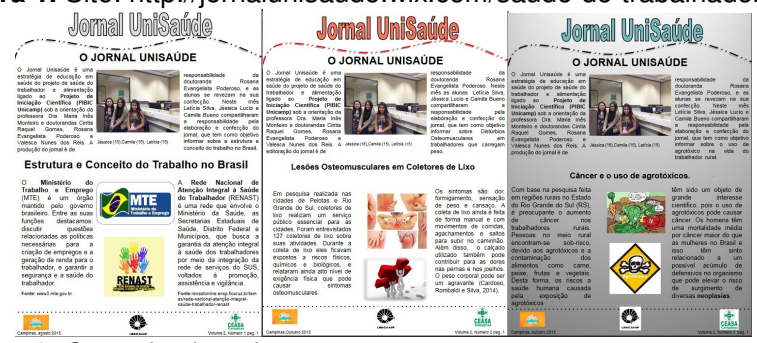

Figura 2. Capa dos jornais 1 a 3

\section{Conclusões}

Foi visível a modificação do comportamento de pesquisa entre os jovens que participam deste projeto sob o ponto de vista de pesquisa de informações confiáveis na Internet. Ao confrontar conteúdo confiável com melhorias de saúde observamos a riqueza de dados e informações que podem ser divulgadas em linguagem acessível a todos os cidadãos, utilizando tecnologia popular, a internet.

O amadurecimento intelectual entre as alunas pôde ser identificado pelo resultado de produção textual que elaboraram de forma autônoma, com base em leitura de artigos científicos e que compuseram os jornais.

\section{Agradecimentos}

UNICAMP e CNPq pela oportunidade e bolsa.

Santos, ARM. O Ministério do Trabalho e Emprego e a saúde e segurança. In:

Saúde e segurança no trabalho no Brasil: aspectos institucionais, sistemas de informação e indicadores. Brasília: Ipea, 2011. Capitulo 1. Acessado em 18 ago 2015. Disponível em: http://www.ipea.gov.br/agencia/images/stories/PDFs/livros/livros/livro_saudenotrabalho.pdf

Alencar, MCB. Distúrbios músculo-esqueléticos e as atividades de trabalho em uma empresa de reciclagem: um enfoque em aspectos físicos. Rev.Ter Ocup; 20(2): 126-134, maio-ago. 2009. Acesso em: 20 set. 2015. Disponível em:

< http://www.revistas.usp.br/rto/article/viewFile/14066/15884>

GregolisTBL, Pinto W de J, Peres Percepção de riscos do uso de agrotóxicos por trabalhadores da agricultura familiar do município de Rio Branco, AC. Rev. Bras. Saúde Ocup[Internet]. 2012June[cited2015Nov03] ;37(125): 99-113. 